\title{
Impairment in bilateral alternating movements in Parkinson's disease?
}

\author{
Dean L Jones, James G Phillips, John L Bradshaw, Robert Iansek, Judy A Bradshaw
}

\begin{abstract}
Although problems in bilateral simultaneous movements in Parkinson's disease (PD) are well known, such deficits have not been reported to be any more impaired than simultaneous movements within the same limb. This is surprising, since (a) the parallels between supplementary motor area (SMA) damage and PD are well documented and (b) the SMA seems to play a special role in bilateral motor control. Bilateral versus unilateral movements in PD were examined by using a task that compared alternating movements of fingers of the same hand with alternating movements of fingers of the opposite hands. PD patients showed particular problems in programming and transferring motor activity to fingers on the opposite side of the body, as opposed to switching motor activity between fingers on the same side of the body. These findings outline the relevance of SMA dysfunction to $\mathbf{P D}$.
\end{abstract}

The "motor circuit" that connects the basal ganglia with the motor cortices includes as a major target the supplementary motor area (SMA). ${ }^{1}$ Parkinson's disease (PD) has been suggested to decrease the output of the basal ganglia to the frontal cortex. ${ }^{2}$ It is thus not surprising that several parallels have been noted between the effects of SMA damage and PD. ${ }^{3-6}$ The SMA, for instance, has been implicated in predictive, "self directed" and sequential movements, which are in fact typical deficits in PD.

The relevance of SMA dysfunction to PD is not completely established, however. The SMA seems to play a part in bilateral motor control, ${ }^{6-8}$ yet PD patients have not been shown to have a special difficulty in bilateral movement control. Unilateral lesions of the monkey's SMA have been reported to produce a long lasting deficit in bimanual coordination, in which the two hands tended to behave in a mirror-like fashion. ${ }^{7}$ The literature on PD reports problems in simultaneous movements of the two hands. ${ }^{910}$ When unimanual and bimanual movements have been compared, however, bimanual movements have not been shown to be disproportionately impaired. ${ }^{112}$

One possible reason for the absence of bilateral deficits in previous studies may be that these studies have examined bilateral simulta- neous movements rather than bilateral alternating movements. That is, subjects with PD may have difficulty in transferring motor activity between the hemispheres. In this regard, it is notable that Laplane et al observed only one lasting deficit in three patients with unilateral SMA ablations: an impairment in performing rapid alternating movements of the hands. ${ }^{8}$ Furthermore, Chan and Ross reported a case of left handed mirror writing following lesion of the right SMA and the nearby medial prefrontal cortex and anterior cingulate gyrus. ${ }^{13}$ The patient's inverted writing was seen to reflect a role of the SMA in non-mirror transformation of motor programmes across the hemispheres. Interestingly, Tashiro et al described nine patients with PD with left handed mirror script. ${ }^{14}$ Thus, difficulty in interhemispheric transfer may be seen in PD patients and may be shown in their production of alternate movements by the two sides. The present study therefore examined the hypothesis that bilateral alternating movements (between fingers from opposite hands) would be more impaired than unilateral alternate movements (between fingers of the same hand).

\section{Method}

Subjects

Ten subjects with idiopathic PD and 10 control subjects participated. All were right handed, and there were seven men and three women in each group. The table shows clinical data, including ratings of symptom severity ${ }^{15}$ and disease progression. ${ }^{16}$

All subjects were screened for evidence of dementia (with the mini-mental state examination (MMSE), ${ }^{17}$ other neurological impairments, and use of neuroleptic and antidepressant drugs. The PD group had a mean age of $65 \cdot 2$ (SD 8.9) years, a mean premorbid IQ of $108(9.0)$ (as estimated by the new adult reading test (NART), ${ }^{18}$ and a mean educational level of $10.4(3.6)$ years. The control group had a mean age of $64.7(7 \cdot 8)$ years, a mean premorbid IQ of $113(5.6)$, and a mean educational level of $9 \cdot 4(1 \cdot 9)$ years.

\section{Design}

The experiment used a $2 \times 2$ design with factors of group (PD and control) and alternation condition (unilateral and bilateral). The procedure was made as sensitive to SMA function as possible. In both alternation condi- 
Table Clinical data of subjects with Parkinson's disease

\begin{tabular}{|c|c|c|c|c|c|c|c|}
\hline Patient & Age & Sex & $\begin{array}{l}\text { Duration of } \\
P D \text { (years) }\end{array}$ & $\begin{array}{l}\text { Webster } \\
\text { rating }\end{array}$ & $\begin{array}{l}\text { PD stage } \\
\text { (Hoehn and Yahr) }\end{array}$ & $\begin{array}{l}\text { Medication } \\
\text { for } P D\end{array}$ & $\begin{array}{l}\text { Dosage } \\
\text { (mg/day) }\end{array}$ \\
\hline 1 & 66 & $\mathbf{M}$ & 15 & 12 & II & $\begin{array}{l}\text { Sinemet } \\
\text { Symmetrel } \\
\text { Kemadrin }\end{array}$ & $\begin{array}{l}375 / 37 \cdot 5^{\star} \\
200 \\
5\end{array}$ \\
\hline 2 & 64 & $\mathbf{M}$ & 20 & 8 & III & $\begin{array}{l}\text { Madopar } \\
\text { Parlodel } \\
\text { Symmetrel } \\
\text { Deprenyl }\end{array}$ & $\begin{array}{c}500 / 125 \\
5 \\
300 \\
10\end{array}$ \\
\hline 3 & 74 & $\mathbf{M}$ & 8 & 8 & I & $\begin{array}{l}\text { Madopar } \\
\text { Symmetrel } \\
\text { Valium }\end{array}$ & $\begin{array}{c}1200 / 300 \\
200 \\
5\end{array}$ \\
\hline 4 & 68 & $\mathbf{M}$ & 16 & 7 & II & $\begin{array}{l}\text { Sinemet } \\
\text { Apomorphine } \\
\text { Deprenyl } \\
\text { Parlodel } \\
\text { Artane }\end{array}$ & $\begin{array}{c}400 / 10 \\
-5 \mathrm{ml} \\
5 \\
30 \\
5\end{array}$ \\
\hline 5 & 64 & $\mathbf{M}$ & 7 & 7 & I & $\begin{array}{l}\text { Madopar } \\
\text { Sinemet } \\
\text { Deprenyl } \\
\text { Artane }\end{array}$ & $\begin{array}{l}400 / 100 \\
500 / 50 \\
5 \\
2\end{array}$ \\
\hline $\begin{array}{l}6 \\
7\end{array}$ & $\begin{array}{l}78 \\
72\end{array}$ & $\begin{array}{l}\mathbf{M} \\
\mathbf{F}\end{array}$ & $\begin{array}{l}2 \\
9\end{array}$ & $\begin{array}{l}11 \\
11\end{array}$ & $\begin{array}{l}\text { II } \\
\text { II }\end{array}$ & $\begin{array}{l}\text { Sinemet } \\
\text { Sinemet }\end{array}$ & $\begin{array}{l}500 / 50 \\
400 / 40\end{array}$ \\
\hline 8 & 49 & $\mathbf{F}$ & 12 & 8 & II & $\begin{array}{l}\text { Madopar } \\
\text { Sinemet } \\
\text { Parlodel }\end{array}$ & $\begin{array}{c}1000 / 250 \\
200 / 20 \\
10\end{array}$ \\
\hline $\begin{array}{r}9 \\
10\end{array}$ & $\begin{array}{l}64 \\
53\end{array}$ & $\begin{array}{l}\mathbf{M} \\
\mathbf{F}\end{array}$ & $\begin{array}{r}8 \\
18\end{array}$ & $\begin{array}{l}12 \\
12\end{array}$ & $\begin{array}{l}\text { II } \\
\text { II }\end{array}$ & $\begin{array}{l}\text { Madopar } \\
\text { Sinemet } \\
\text { Apomorphine }\end{array}$ & $\begin{array}{c}300 / 75 \\
1250 / 125 \\
22 \mathrm{ml}\end{array}$ \\
\hline
\end{tabular}

${ }^{\star}$ Doses for Sinemet and Madopar are shown as mg/day of levodopa or dopamine-decarboxylase inhibitor.

tions, the task encouraged the preparation of sequences of finger movements, for which the SMA seems particularly important. ${ }^{619}$

Two measures were used. Firstly, the time taken to disengage the current movement and programme the next movement was indexed by the time spent holding down the final button of the current sequence (that is, down time (DT)). Secondly, the time taken to engage the new movement was recorded as the time for which neither the final button of the previous sequence nor the first button of the new sequence was depressed (that is, "in flight" or movement time (MT)).

\section{Apparatus}

The experimental task used a response board with a pair of buttons situated within easy access of the subject's left hand $(105 \mathrm{~mm}$ and $135 \mathrm{~mm}$ left of the subject's midline) and a pair of buttons accessible to the right hand (105 $\mathrm{mm}$ and $135 \mathrm{~mm}$ right of the midline). Each button was $13 \mathrm{~mm}$ in diameter. A computer connected to the response board recorded the DT and MT for each button press.

\section{Procedure}

Each hand was used on half of the trials. The subject's index and middle fingers were positioned over the two buttons on the left or right, depending on the hand being used. On each trial, subjects were told two numbers such as "3-1", meaning that they had to press down a button three times with their index or middle finger, and then press an adjacent button once. The subject cycled between the buttons twice (that is, 3-1-3-1). Six sequence combinations (1-3-1-3, 1-5-1-5, 3-1-3-1, 3-5-3-5, 5-1-5-1, and $5-3-5-3$ ) occurred equiprobably and in random order.

The sequence combinations were also used in the bilateral condition. In this case, however, the index fingers were situated over the outer left and outer right buttons. One sequence was performed by the left index finger and the other was performed by the right index finger.

Counterbalancing measures ensured that the order of presentation of the two conditions and the hand and finger to be used first were counterbalanced over subjects. Four practice trials began each of the unilateral and bilateral conditions. Any incorrectly completed trial (that is, too few or too many presses) was aborted and repeated. Ninety six observations were made for each of the two conditons.

\section{Results}

Down time

DT represents the time for which the last button in one sequence was depressed before the subject entered the new sequence on another button. DT was plotted against alternation condition (figure).

A two way ANOVA showed that DT for the PD group tended to be longer $(186 \mathrm{~ms})$ than that of controls $(137 \mathrm{~ms})(F(1,18)=3.30$, $\mathrm{p}<0.09$ ). This was probably a result of a significant interaction of group by alternation condition $(F(1,18)=5.67, \mathrm{p}<0.05)$, where subanalyses indicated that while there were significant differences between the two groups in the bilateral condition $(F(1,18)=4 \cdot 45$, $\mathrm{p}<0.05)$, there were no significant differences between the two groups in the unilateral condition $(F(1,18)=2 \cdot 19, \mathrm{p}<0.05)$.

\section{Movement time}

The MT interval reflects the time over which the subject was changing to the new sequence-the time between release of the last button in one sequence and first depression on the new sequence. MT is shown against alternation condition in the figure. A two way ANOVA showed that the PD group was overall slower than controls (431 v $311 \mathrm{~ms} ; F$ (1, $18)=5.48, p<0.05)$ and that there was a near 

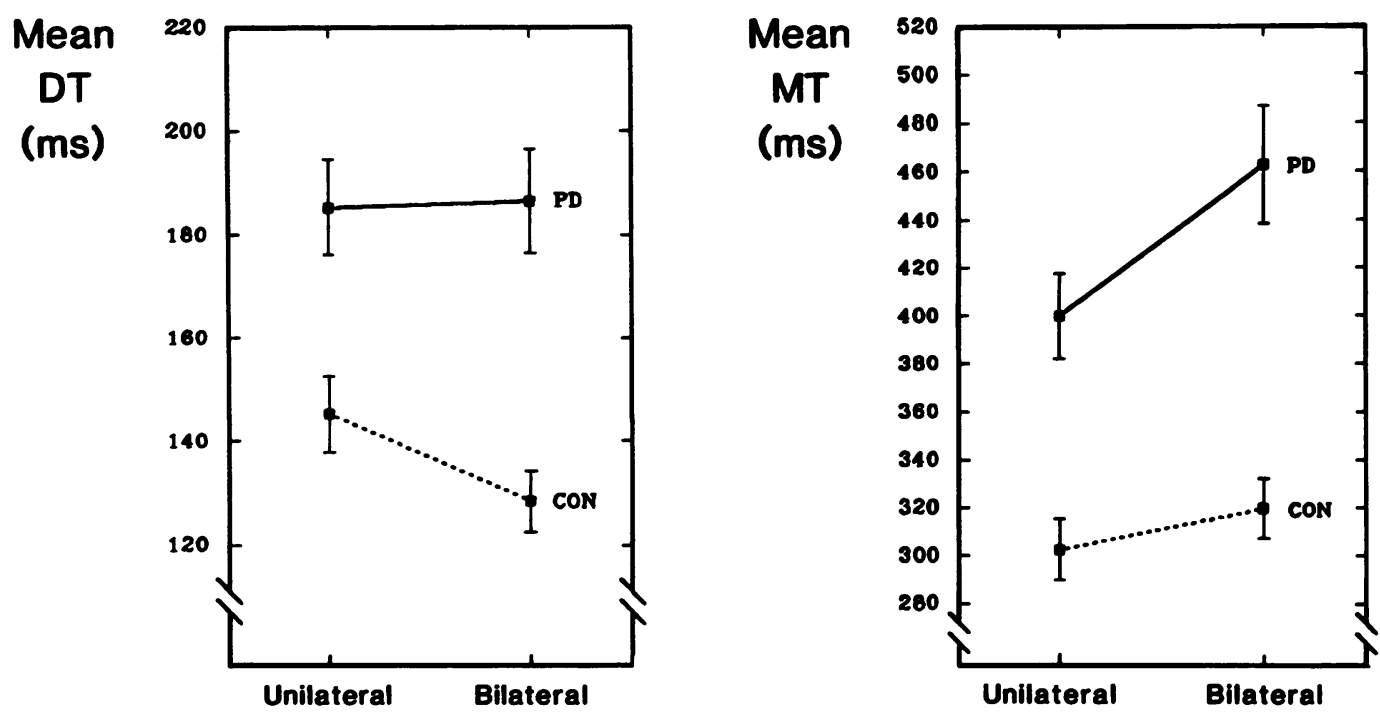

\section{Alternation condition}

Figure Mean down time (DT) and movement time (MT) against unilateral and bilateral alternating movements for Parkinson's disease (PD) and control (CON) subjects.

significant interaction of group by alternation condition, $(F(1,18)=3.51, \mathrm{p}<0.08)$. The cell means for this interaction showed that bilateral switches took only $17 \mathrm{~ms}$ longer than unilateral switches in controls, whereas PD subjects took $63 \mathrm{~ms}$ longer for bilateral over unilateral alternation.

\section{Discussion}

This experiment suggests that subjects with PD may have a disproportionate difficulty in transferring motor activity between fingers on opposite sides of the body, as compared with transfer between fingers on the same side of the body. The difficulty was most apparent in the DT data. DT most likely reflects the termination or disengagement of the previous sequence, as well as the initial programming of the new sequences. ${ }^{20-22}$ Thus, PD might affect the processes of inhibiting a current movement and engaging the preparation of a new movement in the opposite hemisphere. It should also be pointed out, however, that the relevant interaction approached significance for the MT interval after relase. Thus, the execution of the change itself may be somewhat affected by a lack of preprogramming of the new sequence.

Given the well reported role of the SMA in bilateral motor control, ${ }^{46}$ the greater difficulty in bilateral alternation may reflect a dysfunction of the SMA. To date, dysfunction of the SMA has been used to explain PD impairments in "internally" cued or "self directed" movement ${ }^{623}$ and in sequencing action. ${ }^{3}$ The present finding might therefore extend the number of parallels noted between SMA disorder and PD to a deficit in bilateral movement control.

Poor interhemispheric transfer of motor activity may have a number of implications for understanding previous findings in PD. Firstly, the PD patients with left handed mirror writing reported by Tashiro et al $^{14}$ may be showing a problem in the non-mirror transformation of handwriting motor programmes from the left SMA. ${ }^{13}$ Secondly, stuttering - a symptom in some patients ${ }^{15}$ - has long been associated with "aberrant interhemispheric relations" and "disorganisation in interhemispheric integration". ${ }^{25}$ It has even been suggested that SMA dysfunction contributes, at least in part, to this disorder of speech. ${ }^{26}$ Thus, deficits in bilateral control may be relevant to stuttering disorders in PD.

In conclusion, this study suggests that PD may involve an impairment in bilateral alternating movements. In so doing, it may add to a burgeoning literature that emphasises the importance of SMA dysfunction in understanding PD.

This work was supported by a Monash University Research Grant to the second and third authors. We very much appreciate the helpful comments of Dr Malcolm Horne and an anonymous reviewer. We also sincerely thank Dr David Andrewes for access to additional patients, and John Dick, Bob Wood, Mike to additional patients, and John Dick, Bob Wood, Mike
Durham, Frank Devlin, and Truong Nguyen for designing and Durham, Frank Devlin, and Truong Ngu
maintaining the apparatus and software.

1 Alexander GE, DeLong MR, Strick PL. Parallel organization of functionally segregated circuits linking basa ganglia and cortex. Annu Rev Neurosci 1986;9:357-81.

2 Albin RL, Young AB, Penney JB. The functional anatomy of basal ganglia disorders. Trends Neurosci 1989;12:366-75.

3 Benecke R, Rothwell JC, Dick JPR, Day BL, Marsden CD. Disturbance of sequential movements in patients with Parkinson's disease. Brain 1987;110:361-79.

4 Dick JPR, Benecke R, Rothwell JC, Day BL, Marsden CD. Simple and complex movements in a patient with infarction of the right supplementary motor area. Mov infarction of the right
Disord 1986;1:255-66.

5 Evarts EV, Wise SP. Basal ganglia outputs and motor control. Ciba Found Symp 1984;107:83-96.

6 Goldberg G. Supplementary motor area structure and function: review and hypotheses. Behav Brain $S_{c i}$ function: review

7 Brinkman C. Supplementary motor area of the monkey's cerebral cortex: short- and long-term deficits after unilateral ablation and the effects of callosal section. $f$ Neurosci 1984;4:918-29.

8 Laplane D, Talairach J, Meininger V, Bancaud J, Orgogozo JM. Clinical consequences of corticectomies involving the supplementary motor area in man. $f$ Neurol $S c i$ 1977;34:301-14. 
9 Horstink MWIM, Berger HJC, van Spaendonck KPM, van den Bercken JHL, Colls AR. Bimanual simultaneous motor performance and impaired ability to shift attention in Parkinson's disease. $\boldsymbol{f}$ Neurol Neurosurg Psychiatry 1990;53:685-90.

10 Schwab RS, Chafetz ME, Walker S. Control of two simultaneous voluntary motor acts in normals and in simultaneous voluntary motor acts in normals and

11 Benecke R, Rothwell JC, Dick JPR, Day BL, Marsden CD. Performance of simultaneous movements in patients with Parkinson's disease. Brain 1986;109:739-57.

12 Stelmach GE, Worringham CJ. The control of bimanua aiming movements in Parkinson's disease. $f$ Neurol Neurosurg Psychiatry 1988;51:223-31.

13 Chan J-L, Ross ED. Left-handed mirror writing following right anterior cerebral artery infarction: evidence for nonmirror transformation of motor programs by right supplementary area. Neurology 1988;38:59-63.

14 Tashiro K, Matsumoto A, Hamada T, Moriwaka F. The aetiology of mirror Neurosurg Psychiatry 1987;50:1572-8.

15 Webster DD. Critical analysis of the disability of Parkinson's disease. Modern Treatment 1968;5:257-82.

16 Hoehn MM, Yahr MD. Parkinsonism: onset, progression and mortality. Neurology 1967;17:427-42.

17 Folstein MF, Folstein SE, McHugh PR. "Mini-mental state." A practical method for grading the cognitive state of patients for the clinician. $\mathcal{f}$ Psychiatr 1975;12:189-90.

18 Nelson HE O'Connell A. Dementia: the estimation premorbid intelligence levels using the new adult reac est. Cortex 1978;14:234-44.

19 Roland PE, Larsen B, Lassen NA, Skinhøj E. Supplen tary motor area and other cortical areas in organizatio tary motor area and other cortical areas in organizatio voluntary movem.

20 Bradshaw JL, Bradshaw JA, Nettleton NC. Moven initiation and control: abduction, adduction and locu imb. Neuropsychologia 1989;26:701-9.

21 Stelmach GE, Garcia-Colera A, Martin ZE. Force-tra tion control within a movement sequence in Parkins disease. $₹$ Neurol 1989;236:406-10

22 Franks IM, Van Donkelaar P. The effects of deman temporal accuracy on the programming of simple tap sequences. Acta Psychologia 1990;74:1-14.

23 Robertson C, Flowers KA. Motor set in Parkins disease. 7 Neurol Neurosurg Psychiatry 1990;53:583-9

24 Travis LE. Speech pathology. New York: Appleton, 1931 25 Fitzgerald HE, Cooke PA, Greiner JR. Speech and bin ual hand organization in adult stutterers and $\mathrm{I}$ ual hand organization in 1984;9:51-65.

26 Webster WG. Neural mechanisms underlying stutte evidence from bimanual handwriting performance. $E$ Lang 1988;33:226-44. 